\title{
Numerical contribution to airflow study through a generic merchant ship models
}

\author{
BERREZOUG DJAWAD SOUFIANE ${ }^{12}$, BOUZIT MOHAMMED ${ }^{2}$, MERAHI LEILA ${ }^{1}$, BENCHERIF MOHAMMED ${ }^{2}$ \\ ${ }^{1}$ Energy and Naval Propulsion Laboratory, BO 1523 El M'naouer,Oran, ALGERIA \\ ${ }^{2}$ University of Sciences and Technology Mohammed BOUDIAF, BO 1523 El M'naouer, Oran, ALGERIA
}

\begin{abstract}
The merchant ships are continuously recruited by the world meteorological organization (WMO) as Voluntary Observing Ship (VOS) for the collect of meteorological parameters at the ocean surface. VOS meteorological observation includes many parameters such as the wind speed measured by anemometers. This measurement is biased by the presence of ship and superstructure. Little work was carried out in this field. Between them we find the experimental work at a low speed wind tunnel of Southampton University which studies the airflow distortion over simple models (generic models) of VOS merchant ship. This study presents numerical results of a 3D simulation analyzing airflow effect above the bridge of a generic merchant ship models involved in VOS. For this purpose three-dimensional, stationary and turbulent, numerical simulation has been achieved the flow over the bridge of a tanker and a container ship at 1/ 46 scale using a numerical code and
\end{abstract}

CFX code with turbulence k- $\varepsilon$ models. This numerical study allows us to know the position of the line of equality as well as the zone of acceleration and deceleration of the flow. The results obtained numerically by numerical code and CFX code are compared with those obtained experimentally in the wind tunnel of Southampton University. Numerical results are in a good agreement with experimental results and can be used as a reference to find the position of the equality line and to know the error range in of the anemometer velocity reading.

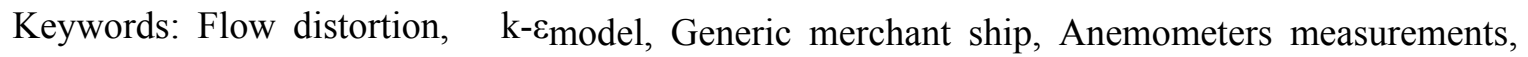
Received: October 10, 2019. Revised: April 27, 2020. Accepted: April 30, 2020. Published: April 30, 2020.

\section{Introduction}

Merchant ships continuously cross the oceans and à large proportion of thème are part of voluntary observation vessels (VOS, contributing to the meteorological parameters collection program such as sea surface temperature, sea state, wind speed and direction etc. The collection of wind speed measurements is made anemometer placed on these ships. These measurements are distorted by the presence of the ships; the flow is accelerated or decelerated compared to free flow.

Among a wind tunnel study performed on ships to determine the wind speed error at anemometer sites, we find the work of Blanc [1, 2] which demonstrated that the wind speed have been distorted by the wind blockage produced by the ship's superstructure, mast, and antennas.

Much work has been developed for the study of the flow on the research ship (Dupuis et al. [3],Kahma Lepparanta [4], Moat et al [5], Popinet et al [6],and Yelland et al $[7,8])$. Few studies have been carried out on merchant vessels (Moat et al [9]).In the case of research ship the anemometers are well exposed, it means on the front mast of the ship. On the other hand, on merchant ship such as the tanker where the ship carries are placed on the bridge where the distortion is severe.

Moat et al [10] in part I for the validation of a CFD model, have been compared between the CFD simulation of the airflow over a bridge of detailed model of the research ship (RSS Charles Darwin) and the in situ wind speed measurement made from the anemometers located above the bridge of this research ship. The simulation showed very good agreement between CFD simulation and in situ results. We have deceleration region above the bridge top which varies in depth with distance backfrom the upwind leading edge. The normalized wind speed increases to a maximum and then decreases within increase in height.

The VOS fleet includes more than 7000 merchant vessels of different types, sizes and shapes; more than $10 \%$ of the vessels in VOS fleet are replaced 
by others each year. It is clearly not stimulate the flow around each individual VOS vessel. MOAT [11] has developed a method to represent the merchant vessels as the tanker, bulk carrier, container ship, cargo ship and others by generic typical ship form.

The study of the flow around the generic models of merchant is comparable to the flow around a block. Many experimental studies on the flow around a block have been made H.Irtaza et al [12], Martinuzzi and Tropead [13], Minson et al [14]and P.J.Richards et al [15]. Many others numerical study of the airflow over the cube have been carried out such as the work of D.Lakehal et al [16], Eason [17], Hee Chang Lim et al [18] ,Murakami et al $[19,20]$ and Rodi et al [21] .

Otherwise, an experimental study was carried out on the generic model of merchant ship. (Davis, [22]), using PIV measurements and segmentation by the smoke process. CFD studies of the flow on generic models of merchant ship are few among them the work of (Moat et al, [10]), which studies the effect of distortion on the tanker and the container ship.

The referenced experiment results have been made at low speed section of the university of Southampton $2.13 \mathrm{~m}$ by $1.52 \mathrm{~m}$ wind tunnel, how was examined the flow over scaled models of the generic merchant ships. In total, three wind studies were performed .We use the results of the Particle Image Velocimetry experiment to validate the CFD studies. The first experiment used thermal probe anemometers to determine the wind speed at different locations in the wind tunnel and above the bridge of the generic merchant ship. The other experiments used the particle image velocimetry system to measure the velocity field above the bridge of the generic merchant ship models. The PIV measurements are taken to determine the flow over the tanker, the container ship and the bloc house block. The low speed section of the Southampton university wind tunnel was $5 \mathrm{~m}$ long with a $4.6 \mathrm{~m}$ by $3.7 \mathrm{~m}$ working cross section. The generic tanker geometry was scaled by $1: 46$ and the generic container ship was made by adding an extrablock to the tanker geometry in order to represent the containers loaded forward of the deck house.

In this numerical study, we will study the flow of air on the generic models of the tanker an the container ship on a reduced scale, using a numerical and CFX code based on the turbulence model k- $\varepsilon$. The results are compared with the experimental study carried out in wind tunnel at the University of Southampton on the tanker and the container ship reduced to 1:46.

\section{Numerical procedure}

The problem being under study involves the steady state motion of a turbulent incompressible fluid of airflow above the bridge of the generic models of merchant ship.

For the numerical code, the partial differential equation governing steady incompressible flows in non-orthogonal coordinates may be written in the following general form as describe in the reference [23]:

$$
\frac{\partial}{\partial x_{i}}\left(C_{i} \varnothing-D_{i \varnothing}\right)=J S_{\varnothing}, i=1,2,3
$$

Where the coefficients $C_{i}$ related to convection, $D_{i \varphi}$ related to diffusion and $\mathrm{S}_{\varphi}$ is the source terms for different dependent variable $\varphi$. $J$ is the Jacobien of coordinate transformation between a general curvilinear system $\left(\mathrm{x}_{\mathrm{i}}\right)$ and a referenced rectangular system $\left(\mathrm{y}_{\mathrm{i}}\right)$.

The numerical codes include four convection differencing schemes: hybrid central/upwind differencing, Quick, SOUCUP and HLPA. For this steady, we use the HLPA differencing schemes.

HLPA (Zhu, [24]) can be written as:

$\emptyset_{w}=\emptyset_{W}+\gamma_{w}\left(\emptyset_{P}-\emptyset_{W}\right) \frac{\emptyset_{W}-\emptyset_{W W}}{\emptyset_{P}-\emptyset_{W W}}$

Where:

$\gamma_{w}=\left\{\begin{array}{rr}1 & \text { if }\left|\emptyset_{W}-0.5\right|<0.5 \\ 0 & \text { otherwise }\end{array}\right.$

The simple algorithm (Patankar and Spalding, [25]) is used to handle the pressure-velocity coupling and the momentum interpolation procedure of Rhie and Chow [26] to avoid spurious oscillations usually encountered with non -staggered grid and the strongly implicit procedure of Stone [27] is used for solving the system of algebraic difference equations, and a height degree of vectorization. The first numerical domain consists of tanker, with a length of $170 \mathrm{~m}$ taken as scaled model for 1:46 scale; placed in a domain of $31.45 \times 12.48 \times 4.59$ meter (see Fig. 1).The calculation grid used was $202 \times 39 \times 264$ (2079792 nodes) for numerical code and 4926594 nodes for CFX code. The second numerical domain consists of container ship, with a length of $170 \mathrm{~m}$ taken as scaled model for 1:46 scale, placed in a domain of $31.45 \times 12.48 \times 4.59$ meter (see Fig. 2). The calculation grid used was $202 \times 46 \times 261$ (2425212 nodes) for numerical code 
and 3704530 nodes for CFX code. The mesh use is mesh structured, non-uniform and orthogonal generated by the numerical code. The $\mathrm{y}+$ value at the wall is between 20 and 100 for each model.

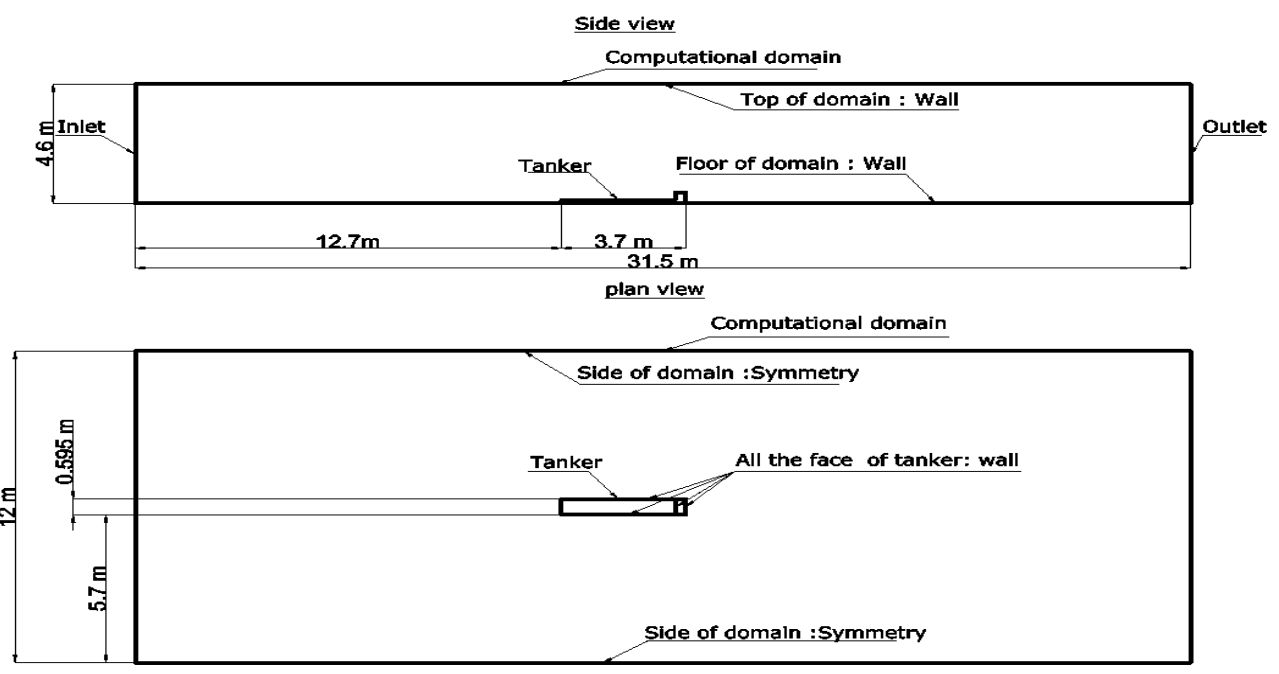

Fig.1. Side and plan views of computational domain of tanker.

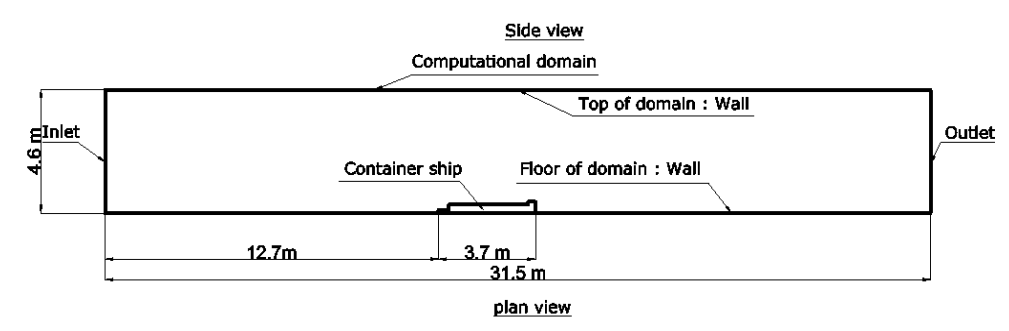

Computational domain

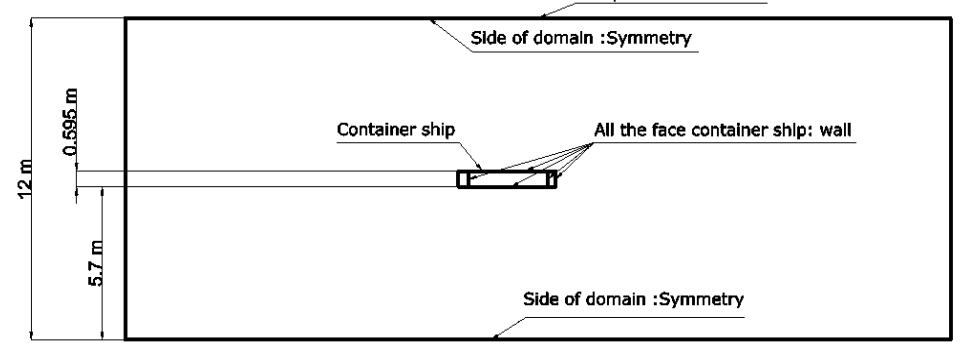

Fig.2. Side and plan views of computational domain of container ship. 


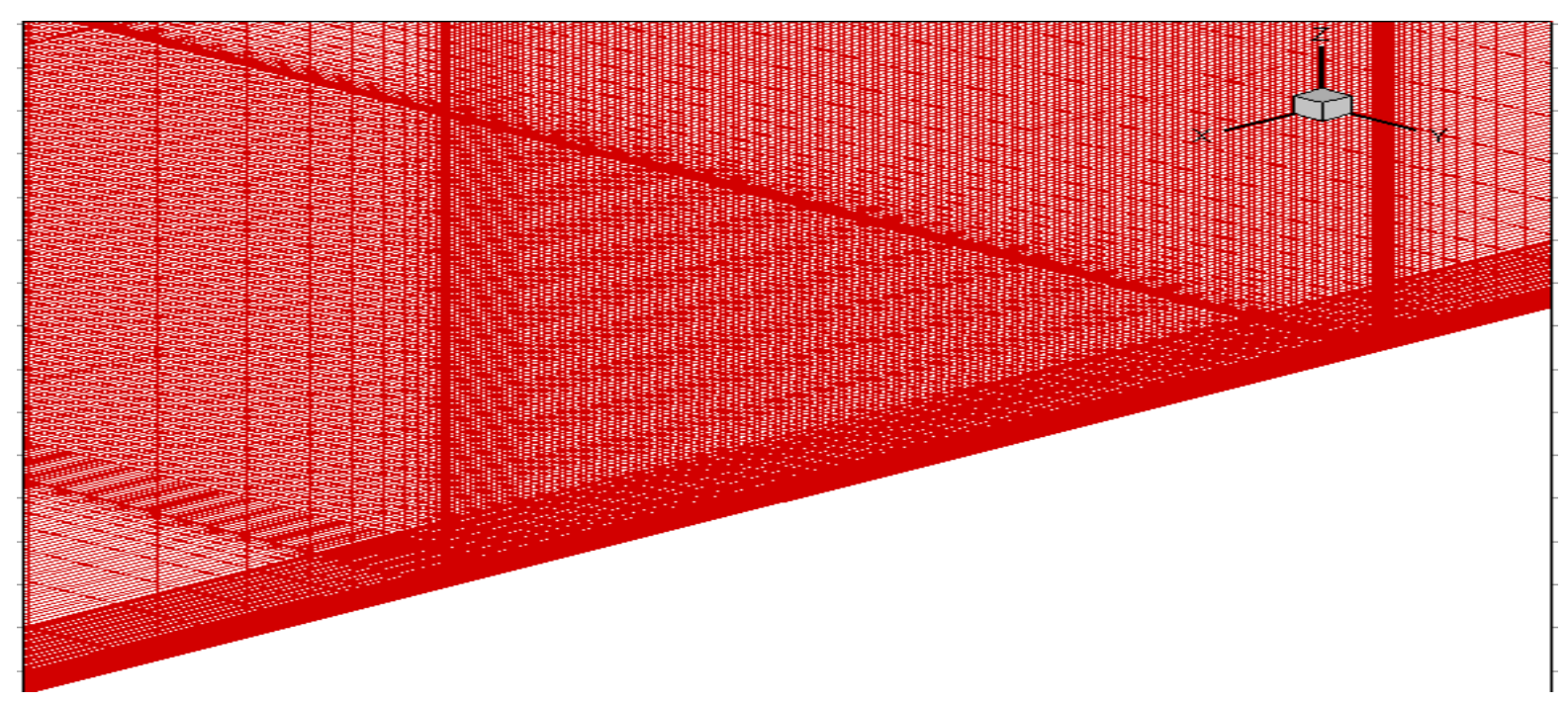

Fig.3. Computational grid mesh of tanker for the numerical code.

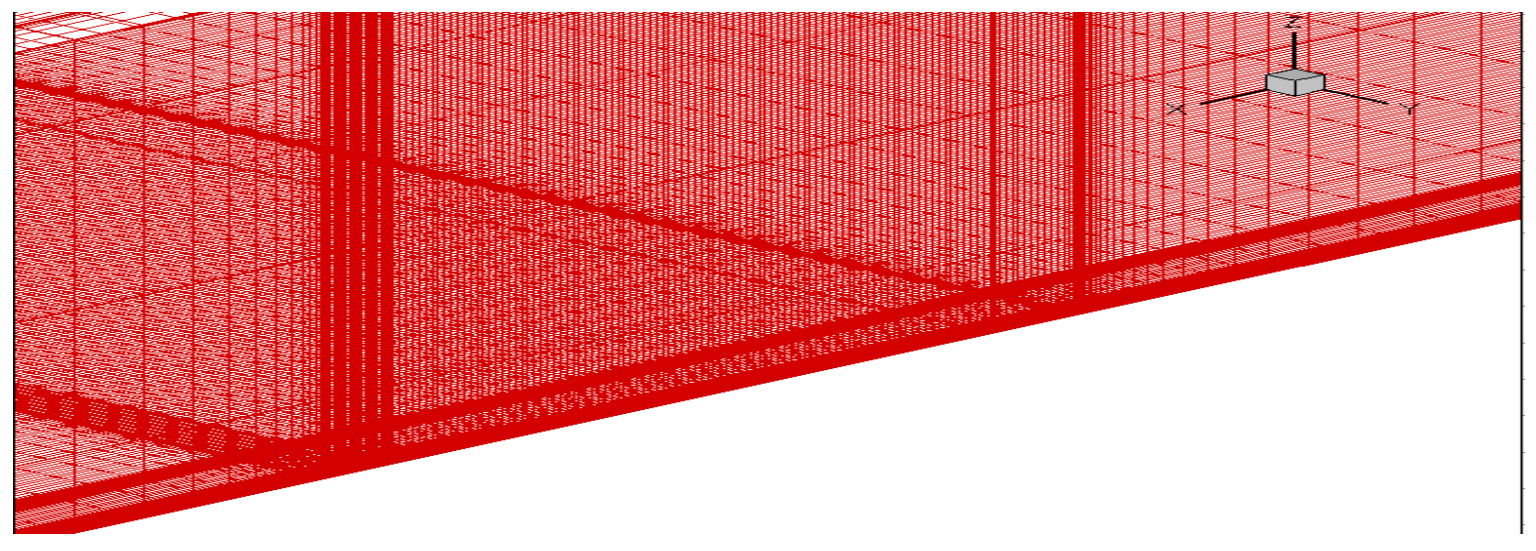

Fig.4. Computational grid mesh of container ship for the numerical code. 


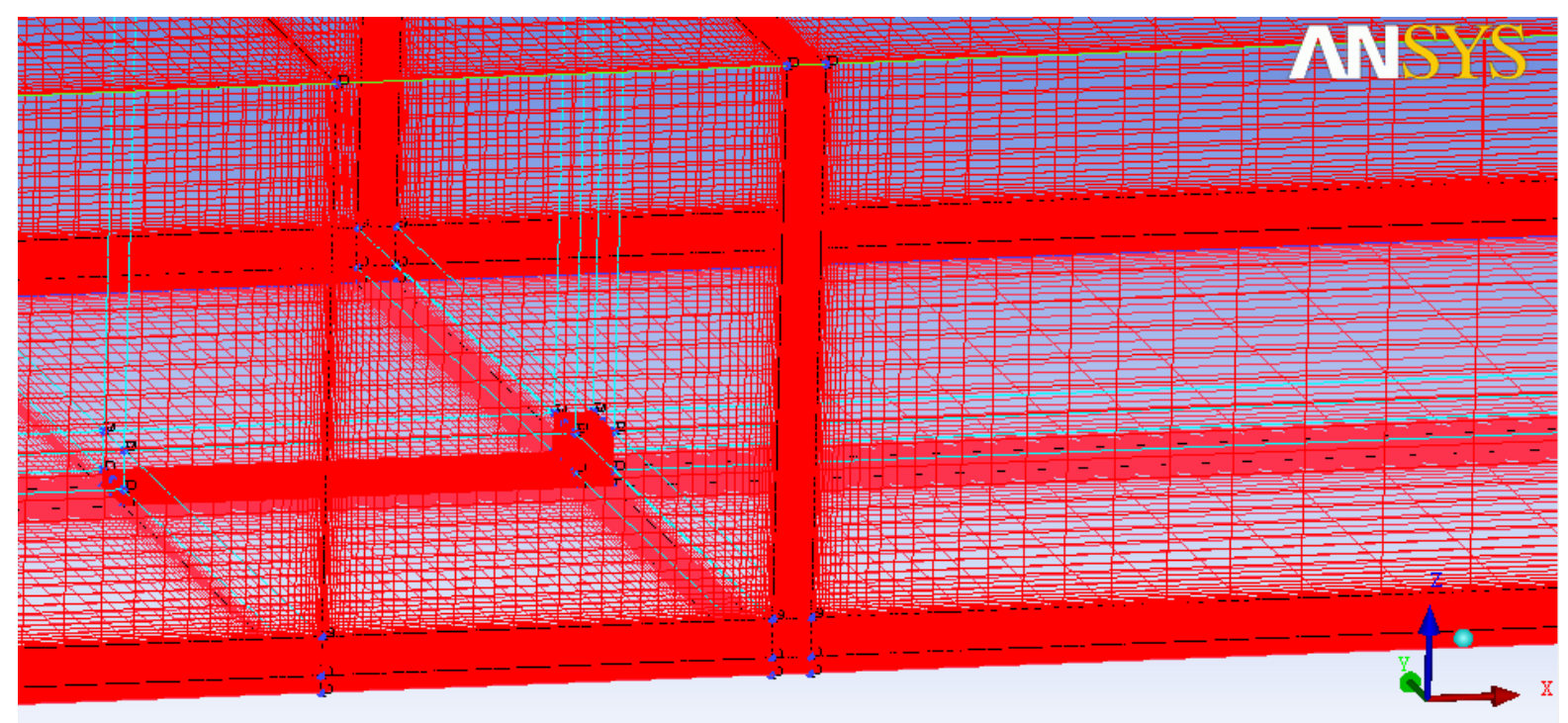

Fig.5. Computational grid mesh of tanker for the CFX code.

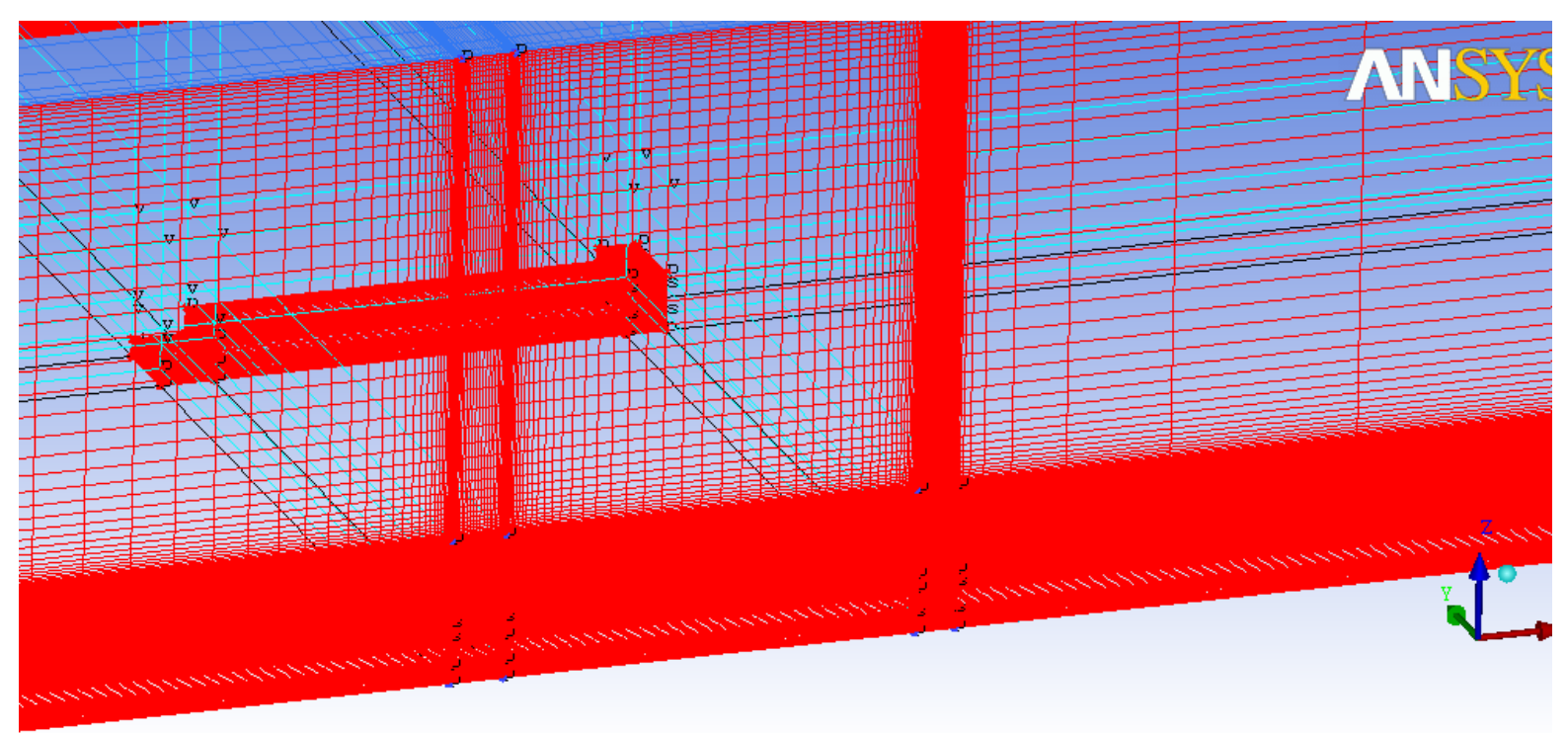

Fig.6. Computational grid mesh of container ship for the CFX code.

\section{Boundary conditions}

Boundary conditions are prescribed at all boundaries of the computational domain. At the mainstream inflow boundary, a constant velocity profile is prescribed of $7 \mathrm{~ms}^{-1}$. The $k$ and $\varepsilon$ profiles are specified using uniform distributions corresponding to a free-stream turbulence intensity of $5 \%$, and a ratio between turbulent and molecular viscosity of 50.At the outflow boundary, the gradients of all flow variables with respect to the stream wise direction are set to zero, and the no-slip condition with wall function approach is applied at the solid walls of tanker or container ship also for the bottom and the top of domain. Symmetry conditions are defined for the south and north wall of the domain.

\section{Results and discussion}

Fig. 7, 8 and 9 shows the vertical profile of the normalized wind speed at absolute distance after the bridge. The vertical scale is the scale of the height of the bridge in meters. The profiles are shown at an absolute distance of 0 meters, 0.09 meters and 0.215 meters. 
The dashed line indicates the normalized wind speed of 1.0 or the measured speed is equal to the free flow velocity.

At $\mathrm{x}=0$ (Fig. 7) for the tanker, in the experiment all the normalized wind speeds are above the speed of the line of equality, but they tend to return to the velocity of free flow. For a numerical code results, the normalized wind speed passes through the line of equality at a height $\mathrm{z}=0.04$, its marks its maximum of 1.1 at a height of $z=0.08$, then returns to the velocity of free flow. Also for the CFX code, the normalized wind speed passes through the line of equality at a height $\mathrm{z}=0.06$, its marks its maximum of 1.03 at a height of $\mathrm{z}=0.11$, then returns to the velocity of free flow. For the container ship, in the experimental all normalized wind speed is above the line speed of equality, but they tend to return to the velocity of free flow.

For numerical code and CFX code results, the normalized wind speed passes through the line of equality at a height $\mathrm{z}=0.16$, it marks its maximum of 1.05 at a height of $z=0.19$, then returns to the velocity of free flow.

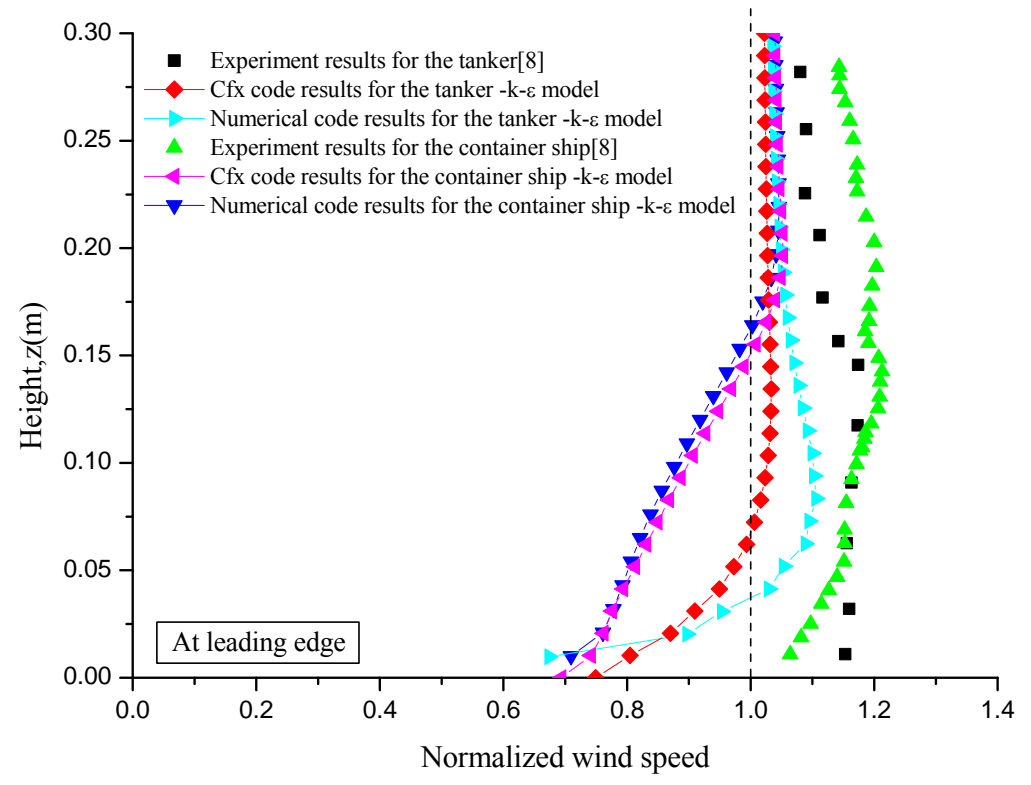

Fig.7. Experimental and numerical comparison of normalized wind speed at leadingedge.

At $\mathrm{x}=0.09$ (fig. 8), for the tanker, in the experimental, the normalized wind speed passes through the line of equality to $\mathrm{z}=0.07$ it marks its maximum of 1.34 at a height $\mathrm{z}=0.09$, then returns to the velocity of free flow. For the numerical code results, the normalized speed passes through the line of equality at a height $\mathrm{z}=$ 0.06 , its marks its maximum of 1.12 at a height $\mathrm{z}$ $=0.09$, then returns to the velocity of free flow.

For the CFX code, the normalized speed passes through the line of equality at a height $\mathrm{z}=0.06$, its marks its maximum of 1.03 at the height $\mathrm{z}=$ 0.1 , then returns to the velocity of free flow.

For the container ship, in the experimental, the normalized wind speed passes through the line of equality to $\mathrm{z}=0.04$ it marks its maximum of
1.29 to $\mathrm{z}=0.07$, then returns to the velocity of free flow. The same for the numerical code and CFX code results, the normalized wind speed passes through the line of equality at a height $\mathrm{z}=0.16$, it marks its maximum of 1.05 at a height of $z=0.18$, then returns to the velocity of free flow.

At $\mathrm{x}=0.215$ (Fig. 9) for tanker, in the experimental, the normalized wind speed passes through the line of equality to $\mathrm{z}=0.11$, it marks its maximum of 1.32 to $\mathrm{z}=0.14$, then returns to the velocity of free flow. The same for the numerical code results, the normalized wind speed passes through the line of equality at a lower height at $\mathrm{z}=0.07$, it marks its 
maximum of 1.13 to $\mathrm{z}=0.11$, then returns to the velocity of free flow.

For the CFX code results, the normalized wind speed passes through the line of equality at a same height as experimental results at $\mathrm{z}=0.11$, it marks its maximum of 1.1 to $\mathrm{z}=0.14$, then returns to the velocity of free flow.

For the container ship, in the experimental, the normalized wind speed passes through the line of equality to $\mathrm{z}=0.06$, it marks its maximum of 1.25 to $\mathrm{z}=0.17$, then returns to the velocity of free flow. The same for numerical code and CFX code results, the normalized wind speed passes through the line of equality at a height $\mathrm{z}=0.15$, it marks its maximum of 1.06 at the height of $z=0.19$, then returns to the velocity of free flow.

Figs 10-13 shows the vertical profile of the normalized wind speed at distance scale (x/ step height) above the bridge. The vertical scale is the height scale (z/step height) above the bridge.
The profiles are shown at distance scales $\mathrm{x} / \mathrm{H}$ of 0 (leading edge), $0.25,0.5$ and 0.75 .

The dashed line indicates the normalized speed of 1.0 or the measured speed is equal to the velocity of free flow.

At the leading edge (Fig. 10), for the tanker and for numerical code, the normalized wind speed increases passes through the line of equality to $\mathrm{z} / \mathrm{H}=0.13$, mark its maximum of 1.1 to $\mathrm{z} / \mathrm{H}=0.28$, then decreases and returns to the velocity of free flow.

For the CFX code, the normalized wind speed increases passes through the line of equality to $\mathrm{z} / \mathrm{H}=0.21$, mark its maximum of 1.03 to $\mathrm{z} / \mathrm{H}=0.44$, then decreases and returns to the velocity of free flow.

For container ship and for numerical and CFX code, the normalized wind speed passes through the line of equality to $\mathrm{z} / \mathrm{H}=1.5$, increases, mark its maximum of 1.03 to $\mathrm{z} / \mathrm{H}=1.65$, then decreases and returns to the velocity of free flow.

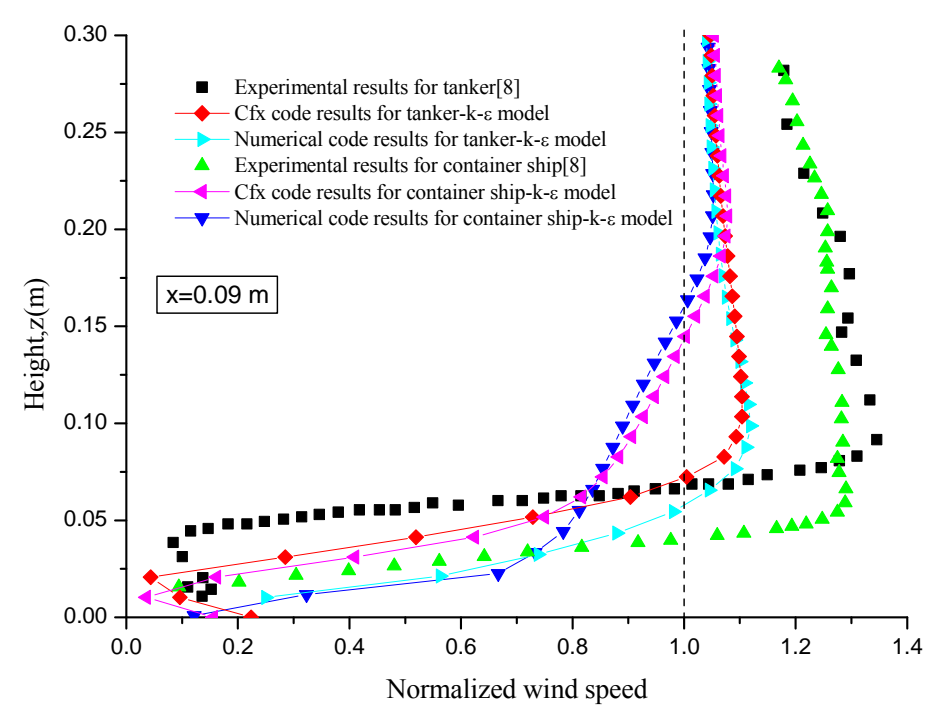

Fig.8. Experimental and numerical comparison of normalized wind speed at $\mathrm{x}=0.09 \mathrm{~m}$. 


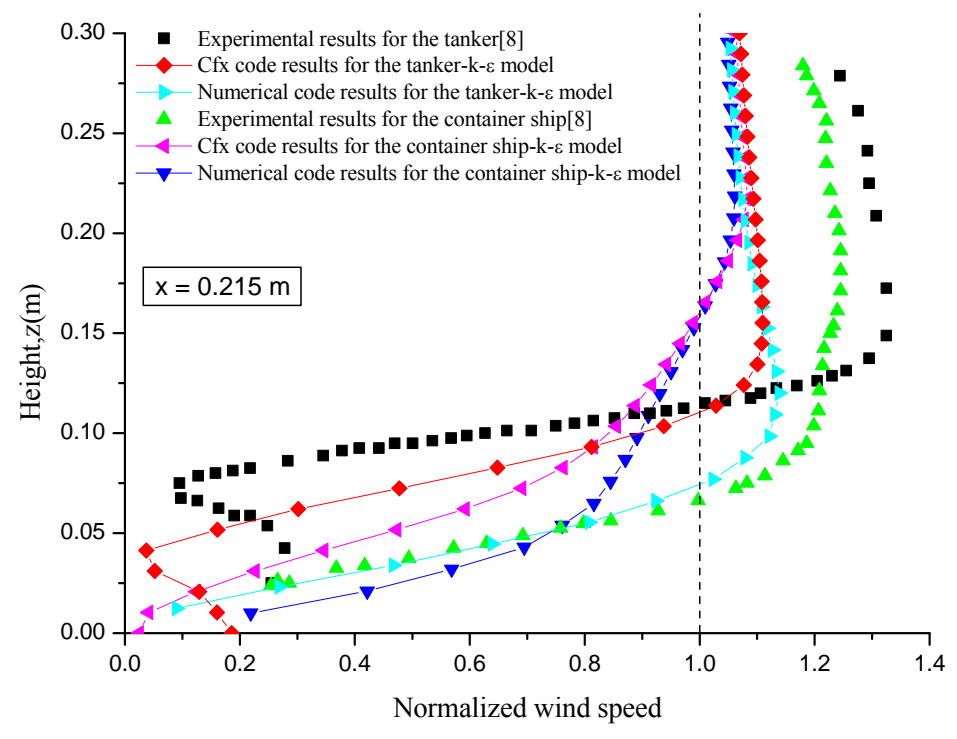

Fig.9. Experimental and Numerical comparison of normalized wind speedatx $=0.215 \mathrm{~m}$.

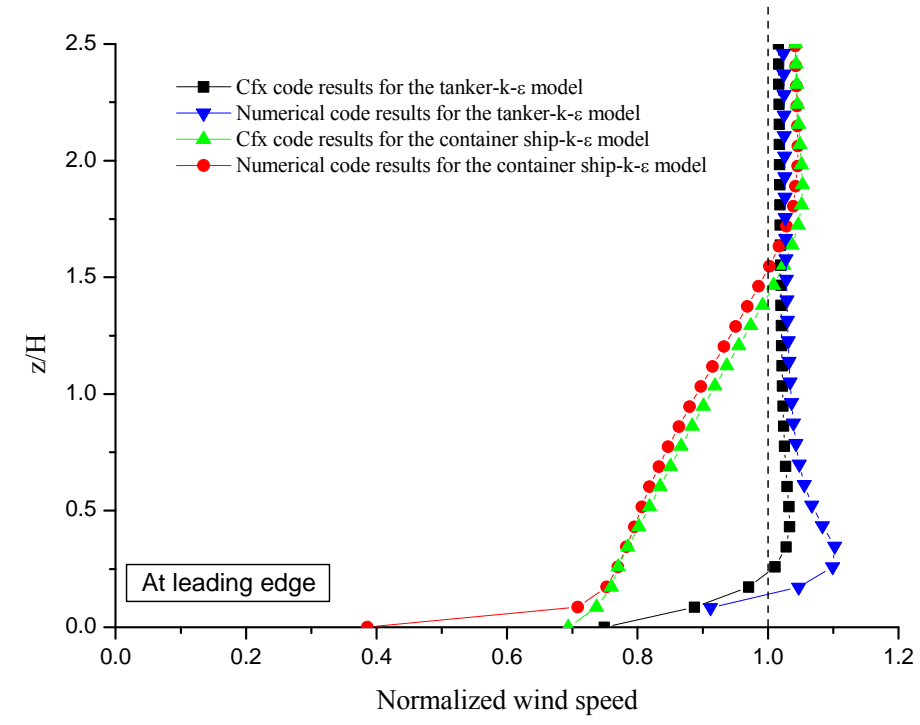

Fig.10. CFD prediction of vertical profiles of normalized wind speed at leading edge.

At $\mathrm{x} / \mathrm{H}=0.25$ (fig. 11) for tanker and for the numerical and CFX code, the normalized wind speed passes through the line of equality to $\mathrm{z} / \mathrm{H}=0.26$ increases until the maximum of 1.14 to $\mathrm{z} / \mathrm{H}=0.4$, then decreases and returns to the velocity of free flow. For container ship and for the numerical and CFX code, the normalized wind speed passes through the line of equality to $\mathrm{z} / \mathrm{H}=1.41$, mark its maximum of 1.04 to $\mathrm{z} / \mathrm{H}=1.65$ then decreases and returns to the velocity of free flow.

At $\mathrm{x} / \mathrm{H}=0.5$ (fig. 12) for tanker and for a numerical and CFX code, the normalized wind speed passes through the line of equality to 
$\mathrm{z} / \mathrm{H}=0.31$ increases until the maximum of 1.11 to $\mathrm{z} / \mathrm{H}=0.47$, then decreases and returns to the velocity of free flow. For container ship and for numerical and CFX code, the normalized wind speed passes through the line of equality to $\mathrm{z} / \mathrm{H}=1.39$, mark its maximum of 1.06 to $\mathrm{z} / \mathrm{H}=1.73$ then decreases and returns to the velocity of free flow.

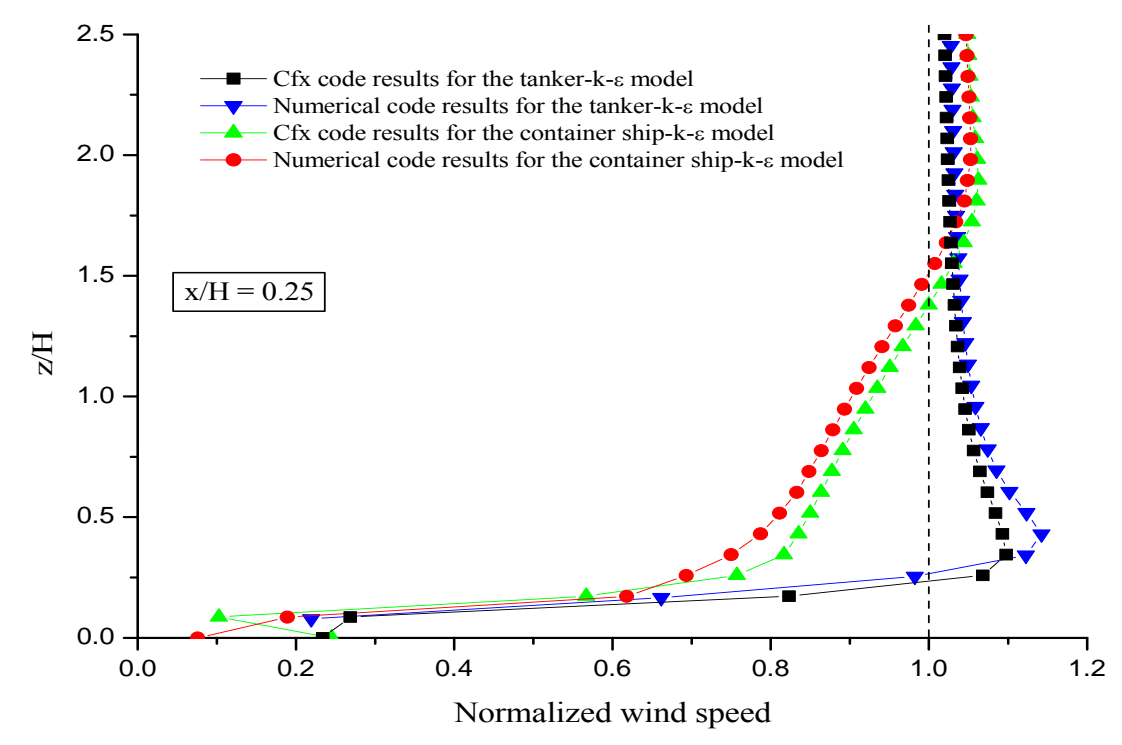

Fig.11. CFD prediction of vertical profiles of normalized wind speed at $\mathrm{x} / \mathrm{H}=0.25$.

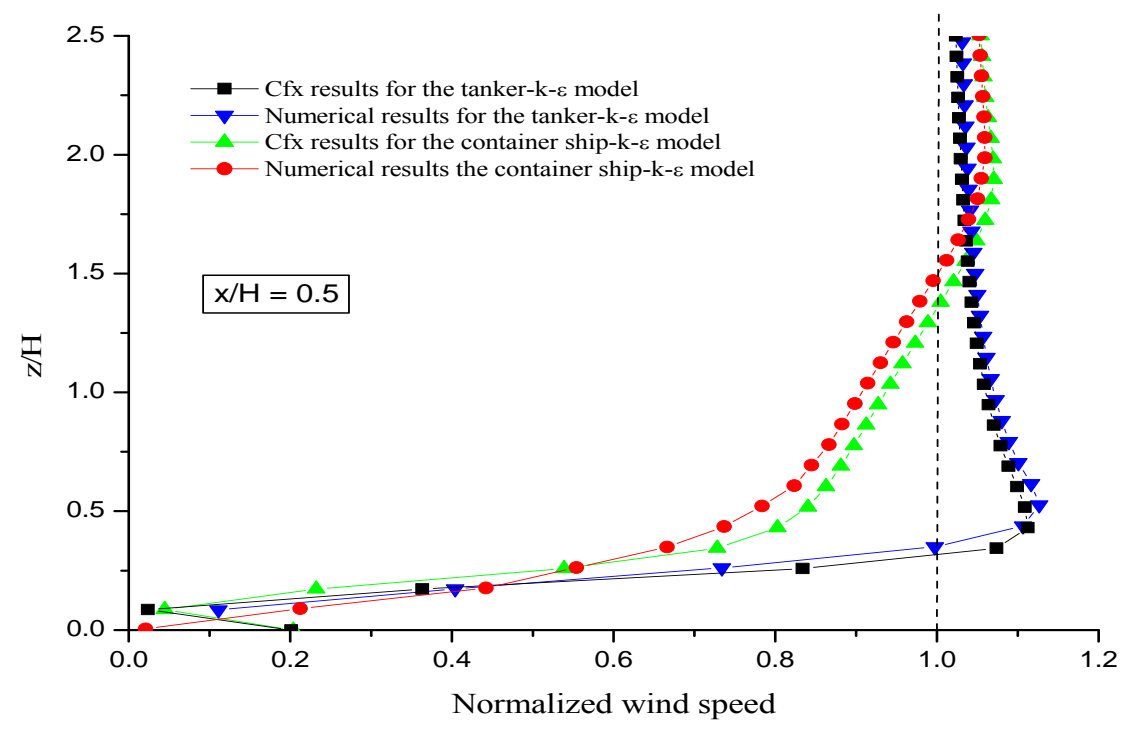

Fig.12. $C F D$ prediction of vertical profiles of normalized wind speed at $\mathrm{x} / \mathrm{H}=0.5$.

At $\mathrm{x} / \mathrm{H}=0.75$ (fig. 13) for tanker and for numerical and CFX code, the normalized wind speed passes through the line of equality to $\mathrm{z} / \mathrm{H}=0.32$ increases until the maximum of 1.11 to $\mathrm{Z} / \mathrm{H}=0.5$, then decreases and returns to the velocity of free flow. For container ship and for numerical and CFX code, the normalized wind speed passes through the line of equality to $\mathrm{z} / \mathrm{H}=1.4$, mark its maximum of 1.04 to $\mathrm{z} / \mathrm{H}=$ 1.68 then decreases and returns to the velocity of free flow. Some relevant studies can be found in [28], [29] and [30]. 


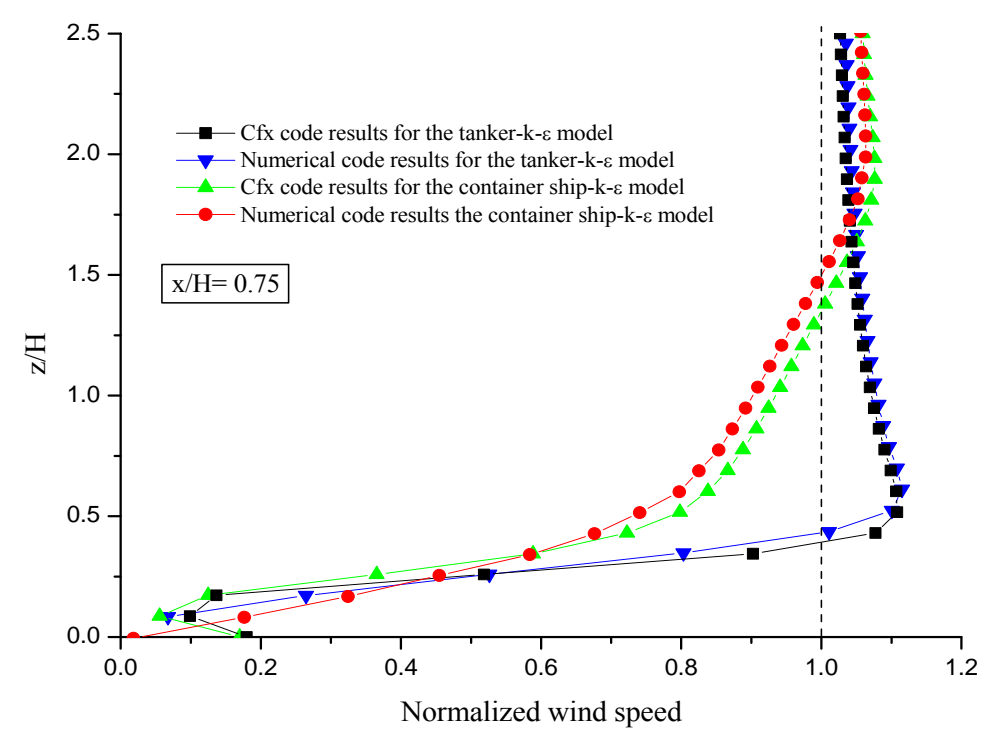

Fig.13. CFD prediction of vertical profiles of normalized wind speed at $\mathrm{x} / \mathrm{H}=0.75$.

\section{Conclusion}

According to the study we conducted, the following results can be drawn:

The numerical results follow have the same pace as the experimental one in the representation of the slip with exception of the main edge. It means that the normalized speed passes through the line of equality, marks its maximum and returns to the speed of the free flow.

The Numerical code and CFX code have the same representation of flow with exception of leading edge how the numerical code have a better prediction of a maximum of velocity.

The height or the normalized speed passes through the equality line varies progressively with the distance from the leading edge for the tanker, on the other hand it is almost the same for container ship.
The height or the normalized speed passes through the equality line varies progressively with the distance from the sharp edge to the tanker.

On the other hand, for container ship the height of the maximum is much larger but varies slightly and almost at the same height.

With the exception of the main edge the height or the normalized speed passes through the equality line varies slightly compared to the experimental one for the tanker, on the other hand for the container ship it has a higher value.

With the exception of the main edge the value or the normalized speed passes through its maximum presents an estimation error of $20 \%$ compared to the experimental one for the tanker, on the other hand for the container ship it has a higher value. 
References :

[1] Blanc, T. V.,Superstructure flow distortion corrections for wind speed and direction measurements made from Tarwa class (LHA1-LHA5) ships, NL Report 9005, Naval Research Laboratory, Washington D. C., 1986.

[2] Blanc, T. V., Superstructure flow distortion corrections for wind speed and direction measurements made from Virginia class (CGN38- CGN41) ships, ,NL Report 9026, Naval Research Laboratory, Washington D.C., 1987.

[3] Dupuis, H., C. Guerin, D. Hauser, A. Weill, P. Nacass, W. M. Drennan, S. Cloché, and H. C. Graber,Impact of flow distortion corrections on turbulent fluxes estimated by theinertial dissipation method during the FETCH experiment on $\mathrm{R} / \mathrm{V}$ L'Atalante,J.Geophys.Res.,108,8064, doi:10.1029/2001JC001075, 2003.

[4] Kahma, K. K., and M. Leppäranta, On errors in wind speed observations on $\mathrm{R} / \mathrm{V}$ Aranda, Geophysica, VOL.17 ,No.1-2, , 1981, pp.155-165.

[5] Bengamin I. Moat,Margaret J. Yelland, Robin W. Pascal and Anthony F. Molland, An overview of the Airflow Distortion at Anemometer sites on Ships, Int. J. Climatol,VOL.25, 2005,pp.997-100.

[6] Popinet, S., M. Smith, and C. Stevens, Experimental and numerical study of the turbulence characteristics of airflow around a research vessel, J. Atmos. Oceanic Technol.,VOL.21, 2004,pp.1575-1589.

[7] Yelland, M. J., B. I. Moat, P. K. Taylor, R. W. Pascal, J. Hutchings, and V. C. Cornell, Wind stress measurements from the open ocean corrected for airflow distortion by the ship,Journal of Physical Oceanography, VOL.28,No.7, 1998, pp.1511-1526.

[8] Yelland, M. J., B. I. Moat, R. W. Pascal and D. I. Berry, CFD Model estimates of the airflow over research ships and the impact on momentum Flux measurements,Journal of Atmospheric and Oceanic Technology, VOL.19,No.10, 2002,pp.1477-1499.

[9] Bengamin I. Moat, Margaret J. Yelland and Anthony F. Molland,Quantifying the Airflow Distortion over Merchant Ships. Part II: Application of the Model Results, Journal of
Atmospheric and Oceanic Technology, VOL.23,No.3, 2006,pp.351-360.

[10] BengaminI. Moat, Margaret J. Yelland, and Robin W. Pascal, Quantifying the Airflow Distortion over Merchant Ships. Part I: Validation of a CFD Model, Journal of Atmospheric and Oceanic Technology, Vol.23,No.3,2006,pp.341-350.

[11] Moat, B. I., Quantifying the effects of airflow distortion on anemometer wind speed measurements from merchant ships,Ph.D. thesis, University of Southampton, Southampton, United Kingdom, 2003.

[12] H.Irtaza,RG.Beale,H.HR.Godley, “ A wind-tunnel investigation into the pressure distribution around sheet-clad scaffolds", $J$. Wind Eng. Ind. Aerodyn, VOL.103 , 2012,pp. 86-95.

[13] Martinuzzi, R, and Tropea, C, The flow around surface mounted prismatic obstacles placed in a fully developed channel flow, Trans ASMEJ fluid Eng,VOL.115,No1, 1993,pp. 8591.

[14] Minson, A. J., C. J. Wood, and R. E. Belcher, Experimental velocity measurements for CFD validation, Journal of Wind Engineering and Industrial Aerodynamics, VOL.58, 1995,pp. 205 -215.

[15] P.J.Richards,R.P.Hoxey,B.D.

Connell,D.P.Lander .Wind-tunnel modelling of the Silsoe cube. Journal of Wind Engineering and Industrial Aerodynamics, VOL.95, 2007,pp.1384-1319,

[16] D. Lakehal ,W.Rodi, "Calculation of the flow past a surface-mounted cube with twolayerturbulence models", Journal of Wind Engineering an Industrial Aerodynamics VOL67-68, 1997, pp .65-78.

[17] Eason, G., Improved Turbulence models for Computational Wind Engineering, $\mathrm{PhD}$. Thesis, University of Nottingham, Nottingham, United Kingdom,2000.

[18] Hee Chang Lim, T.G.Thomas, IanP.Castro, Flow around a cube in a turbulent boundary layer: LES and experiment, Journal of Wind Engineering and Industrial Aerodynamics, VOL.97, 2009, pp.96-109. 
[19] Murakami, S. and A. Mochida, Threedimensional numerical simulation of turbulent flow around buildings using the $k \sim \varepsilon$ Turbulence model, Building and Environment,VOL.24,No.1, 1989,pp. 51-64.

[20] Murakami, S., A. Mochida and Y. Hayashi, " Examining the $k \sim \varepsilon$ model by means of awind tunnel test and large-eddy simulation of the turbulence structure around a cube", Journal of Wind Engineering and Industrial Aerodynamics, VOL.35, 1990,pp.87100.

[21] Rodi, W., " Comparison of LES and RANS calculations of the flow around bluff bodies", Journal of Wind Engineering and Industrial Aerodynamics, VOL.69-71, 1997,pp.55-75.

[22] Davies , P.O.A.L., The new 7x5 Ft. and $15 \times 12 \mathrm{ft}$. low speed wind tunnel at the university of Southampton, A.S.S.U Report Number $N^{\circ} 202$ University of Southampton, UK, 1961.

[23] Zhu J, An Introduction and Guide to the Computer Program FAST-3D, Report No. 691, Institute for Hydromechanics, University of Karlsruhe, 1992.

[24] Zhu.J,Low Diffusivityand oscillation free convection scheme,Communication and applied methods,VOL.7,No.3,1991,pp.225-232.

[25] Patankar S.V. and Spalding D.B. , A calculation procedure for heat, mass and momentum transfer in three-dimensional parabolic flows, Int. J. of Heat and Mass Transfer, VOL.15, 1972, pp.1778-1806.

[26] Rhie,C.M. and Chow,W.L., "Numerical study of the turbulent flow past an Airflow with trailing edge",A/AA Journal, VOL.21,No.11, 1983,pp.1525-1532.

[27] Stone H. L., Iterative Solution of Implicit Approximation of Multidimensional Partial Differential Equations", SIAM J. on Num. Analysis, VOL.5,1968, pp.530-558

[28] Mustapha Helmaoui, Fethi Saidi, Houssem Laidoudi, Aicha Sedini, Abdellah Ghenaim, Layout effect of two Autonomous Underwater Vehicles on the hydrodynamics performances WSEAS Transactions on Systems, pp. 47-54, Volume 19, 2020

[29] Tassadit Chekari, Rachid Mansouri, Maamar Bettayeb, Experimental Validation of IMC-PID-FOF Controllers on the Water Level
Tank System, WSEAS Transactions on Systems and Control, Volume 14, 2019, pp. 460-466 [30] Alexander Blokhin, Ekaterina Kruglova, Boris Semisalov, Modelling of Polymeric Fluid Flow Taking into Account the Electromagnetic Impacts and the Heat Dissipation, WSEAS Transactions on Systems and Control, Volume 14, 2019, pp. 169-182 